\title{
Farelo de Girassol na Alimentação de Frangos de Corte em Diferentes Fases de Desenvolvimento
}

\author{
João Waine Pinheiroํㅗ ${ }^{1}$ Nilva Aparecida Nicolao Fonseca ${ }^{1}$, Caio Abércio da Silva ${ }^{1}$, \\ Lizete Cabrera ${ }^{1}$, Frank Angelo Tomita Bruneli ${ }^{2}$, Sabrina Endo Takahashi ${ }^{2}$
}

RESUMO - Objetivando determinar a melhor idade para a inclusão do farelo de girassol (FG) e o seu melhor nível nas rações de frangos de corte, bem como, avaliar a viabilidade econômica desta inclusão, 480 pintos de corte com 3 dias de idade, metade de cada sexo, foram distribuídos em um delineamento inteiramente ao acaso. Os tratamentos experimentais consistiram de uma combinação de níveis de FG nas rações $(0,4,8$ e 12\%) e idades de fornecimento destas (I1=3-21, I2=22-35 e I3=36-42 dias), sendo: T1=0\% de inclusão de FG nas rações nas idades I1, I2 e I3; T2=4\% nas idades I1, I2 e I3; T3= 8\% nas idades I1, I2 e I3; T4= 12\% nas idades I1, I 2 e I3; T5=0\% na idade I1 e 4\% nas I 2 e I3; T6=0\% na I1 e 8\% nas I 2 e I3, T7=0\% na I1 e 12\% nas I 2 e I3; T $8=0 \%$ nas I1 e I 2 e $4 \%$ na I3; T $9=0 \%$ nas I1 e I2 e 8\% na I3; e T10=0\% nas I1 e I2 e 12\% na I3. As análises estatísticas foram realizadas em arranjos fatoriais 4x2, 7x2 e 10x2, para as características ganho de peso, consumo de ração e conversão alimentar dos 3-21, 3-35 e 3-42 dias, respectivamente. Não houve efeito dos níveis de FG sobre o ganho de peso e consumo de ração nas idades estudadas. Dos 3-35 dias de idade, os tratamentos T1 e $\mathrm{T} 7$ proporcionaram, respectivamente, a melhor e a pior média para conversão alimentar. Aos 42 dias de idade o menor custo de produção foi obtido para o T8.

Palavras-chave: eficiência alimentar, fibra, nutrição

\section{Sunflower Meal in Different Phases of Broiler Development}

\begin{abstract}
The aims of this work were to know the best age to feed poultry with sunflower meal (SM), to determine the best percentage of SM to feed animals in different ages and to evaluate economicall viability of SM as a feeding for poultry ration. In this experiment 480 three days old chicks were distributed in a randomized design. The experimental treatments consisted in rations with different percentages of SM $(0,4,8$ and $12 \%)$ and birds with different ages (I1=3-21 days, I2=21-35 days and I3=36-42 days of age). The treatments were: $\mathrm{T} 1=0 \%$ of SM inclusion on the rations at ages I1, I2 and I3; T2 $=4 \%$ at ages I1, I2 and I3; T3 $=8 \%$ at ages I1, I 2 and $\mathrm{I} 3, \mathrm{~T} 4=12 \%$ at ages $\mathrm{I} 1, \mathrm{I} 2$ and $\mathrm{I} 3, \mathrm{~T} 5=0 \%$ at age $\mathrm{I} 1$ and $4 \%$ at ages $\mathrm{I} 2$ and $\mathrm{I} 3, \mathrm{~T} 6=0 \%$ at age $\mathrm{I} 1$ and $8 \%$ at ages $\mathrm{I} 2$ and $\mathrm{I} 3 ; \mathrm{T} 7=0 \%$ at age $\mathrm{I} 1$ and $12 \%$ at ages $\mathrm{I} 2$ and $\mathrm{I} 3, \mathrm{~T} 8=0 \%$ at ages I1, I 2 and $4 \%$ at age I3, T $9=0 \%$ at ages I1, I 2 and $8 \%$ at age I3; e T10= $0 \%$ at ages I1, I2 and $12 \%$ at age I3. Statistical analyses were carried out in factorial schemes $4 \times 2,7 \times 2$ and $10 \times 2$ to evaluate characteristic weight gain, feed intake and feed conversion rate at 3-21, 3-35 and 3-42 days, respectively. There were no treatments effects on weight gain and on feed intake in the birds age. At 3-35 days of age, treatments T1 and T7 provided respectively the best and the worst feed conversion rate. The lowest production cost was obtained when the animals were fed at treatment $\mathrm{T} 8$.
\end{abstract}

Key Words: feeding efficiency, fiber, nutrition

\section{Introdução}

Os subprodutos da extração de óleo, oriundos principalmente dos grãos de oleaginosas, constituem as principais fontes protéicas nas rações de aves. $\mathrm{O}$ farelo de soja é a principal fonte de proteína nas rações de frangos, no entanto, tem-se observado crescente interesse no uso de outros subprodutos da indústria de óleo vegetal para a fabricação de rações, principalmente do farelo de girassol.

Daghir et al. (1980) afirmaram que 30 a $45 \%$ do grão de girassol é constituído por óleo, que se carac- teriza pela alta concentração de ácidos graxos poliinsaturados, sendo o restante constituído pelo farelo, que é rico em proteína e também em fibra.

De acordo com Bett (1999), a previsão de produção de grãos de girassol no Brasil, no ano de 1999, seria de 50.000 toneladas, o que representaria uma produção entre 27.500 e 35.000 toneladas de farelo de girassol.

Na literatura há variações a respeito da composição bromatológica do farelo de girassol e isto pode ser atribuído às diferentes formas de processamento dos grãos. Minardi (1969) ilustra bem esta caracterís-

\footnotetext{
${ }^{1}$ Docentes do Departamento de Zootecnia - CCA - UEL - Londrina, PR - CEP: 86051-990. E.mail: jwaine@uel.br; nilva@uel.br; casilva@uel.br; Icabrera@uel.br

2 Alunos do curso de Medicina Veterinária - CCA - UEL - Londrina, PR - CEP: 86051-990.
} 
tica. Trabalhos conduzidos pela EMBRAPA (1991) apontam o farelo de girassol como tendo $28,54 \%$ de proteína bruta, $88,57 \%$ de matéria seca, $23,67 \%$ de fibra bruta, $1,35 \%$ de extrato etéreo e $5,32 \%$ de matéria mineral, enquanto o NRC (1994) relata sobre dois tipos de farelos, um com casca, contendo $32 \%$ de proteína bruta, $1.543 \mathrm{kcal} \mathrm{EM} / \mathrm{kg}, 90 \%$ de matéria seca, $24 \%$ de fibra bruta, $1 \%$ de lisina e $0,50 \%$ de metionina, e outro, sem casca, contendo $45,4 \%$ de proteína bruta, 2,320 kcal EM/kg, 93\% de matéria seca, $12,2 \%$ de fibra bruta, $1,24 \%$ de lisina e $0,80 \%$ de metionina.

Concentrações adequadas de proteína e de energia metabolizável na ração, em cada fase de seu desenvolvimento, são condições essenciais para que o frango de corte apresente bom desempenho.

O farelo de girassol, apesar de possuir uma proteína relativamente rica em aminoácidos sulfurados, apresenta, para as rações de frangos, uma deficiência em lisina. Silveira et al. (1967) e Rad \& Keshavarz (1976) demonstraram que, em rações onde o farelo de girassol era a principal fonte dietética de proteína, a adição de lisina melhorava o desempenho das aves.

A alta concentração de fibra no farelo de girassol também é um fator que limita o seu uso na ração das aves. De acordo com Janssen \& Carré (1989), o complexo celulolítico das plantas apresenta baixa digestibilidade pelas aves, aumentando a perda endógena de nutrientes e a diluição da dieta, atuando como barreira que impede a penetração das enzimas na digesta, além de reduzir a concentração de energia das rações. Stringhini et al. (2000) atribuíram como causa do baixo valor de energia metabolizável do farelo de girassol $(1.777 \mathrm{kcal} \mathrm{EM} / \mathrm{kg})$ os seus altos níveis de FDA $(31,68 \%)$ e de FDN $(42,15 \%)$.

Bett (1999) relata que alta concentração de fibra na ração reduz a sua energia metabolizável e o aproveitamento dos seus nutrientes, com conseqüente redução na taxa de crescimento e piora na eficiência alimentar dos frangos de corte. Cita ainda que a substituição do farelo de soja em mais de $10 \%$ por farelo de girassol reduz o coeficiente de metabolização da energia e a concentração da energia bruta das rações.

Diversos estudos foram desenvolvidos com o intuito de otimizar a inclusão do farelo de girassol nas rações de frangos. Waldroup et al. (1970), Costa (1974), Valdivie et al. (1982) e Zatari \& Sell (1990) determinaram que é possível a sua inclusão em até $20 \%$ nas rações de frangos, desde que haja adequada suplementação de lisina e energia. Por sua vez, Ibrahim \& El Zubeir (1991) concluíram que o farelo de girassol pode compor até $30 \%$ da ração sem prejuízo ao desenvolvimento dos frangos. Bett (1999), entretanto, demonstrou ser viável a sua inclusão em até $15 \%$ na ração dos frangos em crescimentoterminação.

Considerando que nas suas diferentes fases de desenvolvimento os frangos de corte devam apresentar um ótimo crescimento, que é resultado do seu metabolismo, o qual está na dependência também de uma ração adequadamente balanceada, o presente trabalho objetivou determinar a melhor idade dos frangos de corte para o uso do farelo de girassol em suas rações, bem como determinar o seu melhor nível de inclusão para as diferentes idades, avaliando-se ainda a viabilidade econômica desta inclusão.

\section{Material e Métodos}

O experimento, com duração de 39 dias, foi realizado no galpão experimental de frangos de corte da Fazenda Escola da Universidade Estadual de Londrina-Pr, no período de 09/11 a 19/12/2000. Foram utilizados 480 pintos de corte com três dias de idade, sendo a metade de cada sexo, em um delineamento inteiramente casualizado, com duas repetições de 12 aves por tratamento e sexo. Os tratamentos experimentais utilizados consistiram de uma combinação de níveis de inclusão (0, 4, 8 e 12\%) de farelo de girassol (FG) nas rações e idades de fornecimento destas rações (I1: 3-21 dias; I2: 22-35 dias e I3: 3642 dias), totalizando 10 tratamentos, conforme apresentado na Tabela 1.

Dentro de cada idade (I1, I2 e I3) as rações foram formuladas de acordo com as exigências nutricionais preconizadas por Rostagno et al. (2000). As suas composições com os devidos níveis de inclusão de farelo de girassol e os valores nutricionais calculados estão na Tabela 2.

As características ganho de peso, consumo de ração e conversão alimentar dos 3-21, 3-35 e 3-42 dias de idade foram analisadas, estatisticamente, utilizando-se, respectivamente, esquemas fatoriais $4 \times 2,7 \times 2$ e 10x2 (tratamentos x sexos), com o uso do programa SAEG (Sistema para Análises Estatísticas e Genéticas) UFV (1997).

Assim, para cada fase estudada, o número de tratamentos utilizados na análise de variância variou em função da combinação de idade e níveis de 
Tabela 1 - Tratamentos em função dos níveis de farelo de girassol nas rações para as diferentes idades dos frangos Table 1 - Treatments in function of sunflower meal levels in rations to different ages of broilers

\begin{tabular}{|c|c|c|c|c|c|c|c|c|c|c|c|c|}
\hline \multirow[t]{2}{*}{$\begin{array}{l}\text { Idade } \\
\text { Age }\end{array}$} & \multicolumn{4}{|c|}{$\begin{array}{l}\text { Idade } 1 \text { (I1) (3-21 dias) } \\
\text { Age } 1 \text { (I1) (3-21 days) }\end{array}$} & \multicolumn{4}{|c|}{$\begin{array}{c}\text { Idade } 2 \text { (I2) (22-35 dias) } \\
\text { Age } 2 \text { (I2) (22-35 days) }\end{array}$} & \multicolumn{4}{|c|}{$\begin{array}{c}\text { Idade } 3 \text { (I3) (36-42 dias) } \\
\text { Age } 3 \text { (I3) (36-42 days) }\end{array}$} \\
\hline & \multicolumn{12}{|c|}{$\begin{array}{l}\text { Nível de inclusão de farelo de girassol (\%) } \\
\text { Sunflower meal level (\%) }\end{array}$} \\
\hline $\begin{array}{l}\text { Tratamentos } \\
\text { Treatments }\end{array}$ & 0 & 4 & 8 & 12 & 0 & 4 & 8 & 12 & 0 & 4 & 8 & 12 \\
\hline $\begin{array}{l}1(0 \% \mathrm{I} 1, \mathrm{I} 2 \text { e I } 3) \\
2(4 \% \mathrm{I} 1, \mathrm{I} 2 \text { e I3 } 3)\end{array}$ & $\mathrm{X}$ & $\mathrm{X}$ & & & $\mathrm{X}$ & $\mathrm{X}$ & $\mathrm{Y}$ & & $\mathrm{X}$ & $\mathrm{X}$ & $\mathrm{V}$ & \\
\hline $4(12 \% \mathrm{I} 1, \mathrm{I} 2 \mathrm{e} \mathrm{I} 3)$ & & & $X$ & $\mathrm{X}$ & & & $X$ & $\mathrm{X}$ & & & $X$ & $\mathrm{X}$ \\
\hline $5(0 \% \mathrm{I} 1,4 \% \mathrm{I} 2$ e I3) & $X$ & & & & & $\mathrm{X}$ & & & & $\mathrm{X}$ & & \\
\hline $6(0 \% \mathrm{I} 1,8 \% \mathrm{I} 2$ e I3) & $\mathrm{X}$ & & & & & & $\mathrm{X}$ & & & & $\mathrm{X}$ & \\
\hline $7(0 \% \mathrm{I} 1,12 \% \mathrm{I} 2$ e I3) & $X$ & & & & & & & $\mathrm{X}$ & & & & $\mathrm{X}$ \\
\hline $8(0 \%$ I 1 e $\mathrm{I} 2$ e $4 \%$ I 3$)$ & $X$ & & & & $\mathrm{X}$ & & & & & $\mathrm{X}$ & & \\
\hline $9(0 \%$ I1 e I 2 e $8 \%$ I3 $)$ & $X$ & & & & $\mathrm{X}$ & & & & & & $\mathrm{X}$ & \\
\hline $10(0 \%$ I 1 e I 2 e $12 \%$ I 3$)$ & $\mathrm{X}$ & & & & $\mathrm{X}$ & & & & & & & $\mathrm{X}$ \\
\hline
\end{tabular}

inclusão de farelo de girassol, ou seja, na fase de 3 a 21 , de 3 a 35 e de 3 a 42 dias de idade foram aplicados os tratamentos de 1 a 4 , de 1 a 7 e de 1 a 10 , respectivamente. As diferenças obtidas entre as médias foram testadas pelo teste de Tukey a $5 \%$ de probabilidade.

Os preços dos ingredientes utilizados na elaboração dos custos das rações (Tabela 2) foram obtidos na região de Londrina-Pr, no mês de março de 2001, a saber: milho R \$ 0,14/kg; farelo de soja R $\$ 0,395 / \mathrm{kg}$; farelo de girassol R \$0,145/kg; óleo de soja $\mathrm{R} \$ 0,65 / \mathrm{kg}$; calcário R $\$ 0,065 / \mathrm{kg}$; fosfato bicálcico R $\$ 0,60 / \mathrm{kg}$; sal comum R \$ 0,12/kg; Dl-metionina R \$ 7,50/kg; L-lisina $\mathrm{R} \$ 4,92 / \mathrm{kg}$; cloreto de colina R $\$ 2,50 / \mathrm{kg}$; suplemento vitamínico/mineral (SEWEMIX) R \$16,64/kg.

Para verificar a viabilidade econômica da inclusão do farelo de girassol nas rações, determinou-se o custo médio em ração, por quilograma de peso vivo ganho (Yi), durante operíodo experimental(Bellaveretal., 1985).

$$
\mathrm{Yi}=(\mathrm{Q} i \times \mathrm{P} i) / G i,
$$

em que: $Y i$ = custo médio em ração por quilograma ganho no $i$-ésimo tratamento; $\mathrm{P} i=$ preço médio por quilograma da ração utilizada no $i$-ésimo tratamento; $\mathrm{Q} i=$ quantidade média de ração consumida no $i$-ésimo tratamento; $\mathrm{G} i=$ ganho médio de peso do $i$-ésimo tratamento.
Em seguida, foram calculados o Índice de Eficiência Econômica (IEE) e o Índice de Custo médio (IC), propostos por Barbosa et al. (1992).

$$
\mathrm{IEE}=[(\mathrm{MC} e) / \mathrm{Ct} e i] \times 100 \text { e IC }=[(\mathrm{CT} e i) / \mathrm{Mce}]
$$$$
x 100 \text {, }
$$

em que: $\mathrm{MCe}=$ menor custo médio em ração, por quilograma de peso vivo ganho, observado entre os tratamentos; $\mathrm{CT} e i=$ custo médio do tratamento $i$ considerado.

\section{Resultados e Discussão}

Desempenho dos frangos no periodo entre 3 e 21 dias de idade

As médias de desempenho dos frangos de corte entre 3 e 21 dias de idade estão na Tabela 3.

Como pode ser observado, não houve efeito significativo $(\mathrm{P}>0,05)$ dos diferentes tratamentos experimentais sobre as variáveis estudadas.

Isto demonstra que, nesta fase de desenvolvimento, é possível a inclusão de $12 \%$ de farelo de girassol na ração, sem que haja qualquer comprometimento no desempenho dos frangos de corte.

Este valor está bastante próximo ao recomendado por Bett (1999), que determinou como ideal, em 
Tabela 2 - Composição percentual e calculada das rações experimentais

Table 2 - Percentage and calculated composition of the experimental rations

\begin{tabular}{|c|c|c|c|c|c|c|c|c|c|c|c|c|}
\hline \multirow[t]{2}{*}{$\begin{array}{l}\text { Ingredientes } \\
\text { Ingredients }\end{array}$} & \multicolumn{4}{|c|}{$\begin{array}{l}\text { Idade } 1 \text { (I1) (3-21 dias) } \\
\text { Age } 1 \text { (II) (3-21 days) }\end{array}$} & \multicolumn{4}{|c|}{$\begin{array}{c}\text { Idade } 2 \text { (I2) (22-35 dias) } \\
\text { Age } 2 \text { (I2) (22-35 days) }\end{array}$} & \multicolumn{4}{|c|}{$\begin{array}{c}\text { Idade } 3 \text { (I3) (36-42 dias) } \\
\text { Age } 3 \text { (I3) (36-42 days) }\end{array}$} \\
\hline & 0 & 4 & 8 & 12 & 0 & 4 & 8 & 12 & 0 & 4 & 8 & 12 \\
\hline $\begin{array}{l}\text { Milho } \\
\text { Corn }\end{array}$ & 59,15 & 55,90 & 52,63 & 49,36 & 63,80 & 60,58 & 57,32 & 54,05 & 67,00 & 63,67 & 60,37 & 57,05 \\
\hline $\begin{array}{l}\text { Farelo de soja } \\
\text { Soybean meal }\end{array}$ & 35,19 & 33,35 & 31,52 & 29,68 & 30,62 & 28,78 & 26,94 & 25,10 & 27,33 & 25,57 & 23,78 & 22,00 \\
\hline $\begin{array}{l}\text { Farelo de girassol } \\
\text { Sunflower meal }\end{array}$ & 0,00 & 4,00 & 8,00 & 12,00 & 0,00 & 4,00 & 8,00 & 12,00 & 0,00 & 4,00 & 8,00 & 12,00 \\
\hline $\begin{array}{l}\text { Óleo vegetal } \\
\text { Vegetable oil }\end{array}$ & 1,79 & 2,83 & 3,88 & 4,92 & 2,08 & 3,09 & 4,12 & 5,17 & 2,67 & 3,73 & 4,79 & 5,85 \\
\hline $\begin{array}{l}\text { Calcário } \\
\text { Limestone }\end{array}$ & 0,985 & 0,985 & 0,980 & 0,978 & 0,895 & 0,895 & 0,89 & 0,89 & 0,955 & 0,954 & 0,952 & 0,951 \\
\hline $\begin{array}{l}\text { Fosfato bicálcico } \\
\text { Dicalcium phosphate }\end{array}$ & 1,815 & 1,848 & 1,881 & 1,914 & 1,65 & 1,685 & 1,72 & 1,75 & 1,47 & 1,50 & 1,54 & 1,57 \\
\hline $\begin{array}{l}\text { Sal } \\
\text { Salt }\end{array}$ & 0,454 & 0,460 & 0,466 & 0,471 & 0,411 & 0,417 & 0,422 & 0,428 & 0,317 & 0,323 & 0,330 & 0,336 \\
\hline $\begin{array}{l}\mathrm{DL}-\text { Metionina } 99 \% \\
\text { DL-methionine } 99 \%\end{array}$ & 0,234 & 0,228 & 0,226 & 0,216 & 0,182 & 0,178 & 0,173 & 0,169 & 0,051 & 0,046 & 0,041 & 0,036 \\
\hline $\begin{array}{l}\mathrm{L}-\mathrm{Lisina} \mathrm{HCl} 78,5 \% \\
\mathrm{HCl} \text { L-lysine } 78,5 \%\end{array}$ & 0,174 & 0,200 & 0,222 & 0,253 & 0,158 & 0,186 & 0,214 & 0,243 & 0,00 & 0,00 & 0,00 & 0,024 \\
\hline $\begin{array}{l}\text { Cloreto de colina } \\
\text { Choline cloride }\end{array}$ & 0,100 & 0,100 & 0,100 & 0,100 & 0,100 & 0,100 & 0,100 & 0,100 & 0,100 & 0,10 & 0,10 & 0,10 \\
\hline $\begin{array}{l}\text { Supl. Vit. + Mineral } \\
{ }^{1} \\
\text { Vit. - Min. supplement }\end{array}$ & 0,100 & 0,100 & 0,100 & 0,100 & 0,100 & 0,100 & 0,100 & 0,100 & 0,100 & 0,10 & 0,10 & 0,10 \\
\hline $\begin{array}{l}\text { Custo } / \mathrm{Kg} \\
\text { Cost } / \mathrm{Kg}\end{array}$ & 0,291 & 0,293 & 0,294 & 0,296 & 0,275 & 0,277 & 0,279 & 0,281 & 0,241 & 0,242 & 0,243 & 0,245 \\
\hline $\begin{array}{l}\text { Valor calculado } \\
\text { Calculated value }\end{array}$ & & & & & & & & & & & & \\
\hline $\begin{array}{l}\mathrm{EM}(\mathrm{kcal} / \mathrm{kg}) \\
M E(\mathrm{Kcal} / \mathrm{Kg})\end{array}$ & 3000 & 3000 & 3000 & 3000 & 3075 & 3075 & 3075 & 3075 & 3150 & 3150 & 3150 & 3150 \\
\hline $\begin{array}{l}\text { Proteína bruta }(\%) \\
\text { Crude protein }(\%)\end{array}$ & 21,4 & 21,4 & 21,4 & 21,4 & 19,69 & 19,69 & 19,69 & 19,69 & 18,2 & 18,2 & 18,2 & 18,2 \\
\hline $\begin{array}{l}\text { Cálcio }(\%) \\
\text { Calcium }(\%)\end{array}$ & 0,960 & 0,960 & 0,960 & 0,960 & 0,88 & 0,88 & 0,88 & 0,88 & 0,85 & 0,85 & 0,85 & 0,85 \\
\hline $\begin{array}{l}\text { Fósforo disponível (\%) } \\
\text { Available phosphorus (\%) }\end{array}$ & 0,450 & 0,450 & 0,450 & 0,450 & 0,41 & 0,41 & 0,41 & 0,41 & 0,41 & 0,375 & 0,375 & 0,375 \\
\hline $\begin{array}{l}\text { Metionina }+ \text { cistina }(\%) \\
\text { Methionine }+ \text { cystine }(\%)\end{array}$ & 0,897 & 0,897 & 0,897 & 0,897 & 0,83 & 0,83 & 0,83 & 0,83 & 0,667 & 0,665 & 0,665 & 0,665 \\
\hline $\begin{array}{l}\text { Lisina }(\%) \\
\text { Lysine (\%) }\end{array}$ & 1,263 & 1,263 & 1,263 & 1,263 & 1,16 & 1,16 & 1,16 & 1,16 & 0,950 & 0,932 & 0,911 & 0,909 \\
\hline $\begin{array}{l}\text { Fibra bruta (\%) } \\
\text { Crude fiber (\%) }\end{array}$ & 3,24 & 3,93 & 4,63 & 5,33 & 3,23 & 3,93 & 4,60 & 5,30 & 3.08 & 3,77 & 4,46 & 5,14 \\
\hline
\end{tabular}

${ }^{1}$ Suplemento vitamínico e mineral - Composição por kg de produto (Vitaminic and mineral suplement.- Composition per kg of product): Inicial (initial). vit. A $10.000 .000 \mathrm{UI}$; vit D3 2.000.000 Ul; vit E 20.000 mg; vit K3 2.600 mg; vit B1 $1.800 \mathrm{mg}$; vit B2 5.000 mg; vit B6 $2.500 \mathrm{mg}$; vit B12 $15 \mathrm{mcg}$; niacina (niacin) $40.000 \mathrm{mg}$; ácido fólico (folacin) $900 \mathrm{mg}$; ác. pantotênico (pantothenic acid) $12.000 \mathrm{mg}$; biotina (biotine) $80 \mathrm{mg}$; selenito de sódio (selenium) $600 \mathrm{mg}$; antioxidante (antioxidant) $120 \mathrm{~g}$; cobalto (Cobalt) $51 \mathrm{mg}$; cobre (Copper) $6.300 \mathrm{mg}$; enxofre (sulfate) $13.300 \mathrm{mg}$; ferro (iron) $50.400 \mathrm{mg}$; iodo (iodine) $650 \mathrm{mg}$; manganês (manganese) $17.500 \mathrm{mg}$; zinco (zinc) $36.500 \mathrm{mg}$; veículo q.s.p. (veicle q.s.p.) 1.000 g. Final (Final) vit. A 8.000.000 UI; vit D3 1.700 .000 UI; vit E 18.000 mg; vit K3 1.800 mg; vit B1 1.200 mg; vit B2 4.000 mg; vit B6 $1.500 \mathrm{mg}$; vit B12 $10 \mathrm{mcg}$; niacina (niacine) $30.000 \mathrm{mg}$; ácido fólico (folacin) $500 \mathrm{mg}$; ác. pantotênico (pantothenic acid) $12.000 \mathrm{mg}$; biotina (biotin) $20 \mathrm{mg}$; selenito de sódio (selenium) $274 \mathrm{mg}$; cobalto (cobalt) $51 \mathrm{mg}$; cobre (copper) $6.300 \mathrm{mg}$; enxofre (sulfate) $13.300 \mathrm{mg}$; ferro (iron) $50.400 \mathrm{mg}$; iodo (iodine) $650 \mathrm{mg}$; manganês (manganese) $17.500 \mathrm{mg}$; zinco (zinc) $36.500 \mathrm{mg}$; veículo q.s.p. (veicle qsp) $1.000 \mathrm{~g}$. 
rações de frangos de corte de 1 a 21 dias de idade, os níveis de $14,23 \%$ e de $13,17 \%$ para ótima conversão alimentar e consumo de ração, respectivamente, e cita que o ganho de peso dos frangos foi normal para até $28,48 \%$ de farelo de girassol na ração.

Outros pesquisadores, como Rad \& Keshavarz (1976) e Musharaf (1991), contudo, relataram que rações iniciais de frangos de corte podem conter até $17,5 \%$ e $25 \%$ de farelo de girassol, respectivamente.

Waldroup et al. (1970), Rad \& Keshavarz (1976) e Valdivie et al. (1982) também demonstraram a viabilidade do uso do farelo de girassol em rações fareladas de pintos, desde que fossem adequadamente suplementadas com energia e lisina.

Para as variáveis ganho de peso e consumo de ração os machos apresentaram maiores médias $(\mathrm{P}<0.01)$ que as fêmeas, enquanto que para a conversão alimentar não houve diferença $(\mathrm{P}>0.05)$ entre os sexos.

Desempenho dos frangos no periodo entre 3 e 35 dias de idade

Os resultados de desempenho dos frangos de corte no período entre 3 e 35 dias de idade se encontram na Tabela 4.

Como se observa, os diferentes tratamentos experimentais não afetaram $(\mathrm{P}>0.05)$ o consumo de ração e o ganho de peso. No entanto, a melhor conversão alimentar $(\mathrm{P}<0.05)$ foi obtida quando os frangos foram submetidos ao tratamento T1, ou seja, quando consumiram a ração sem inclusão de farelo de girassol.

Embora as médias de ganho de peso não tenham apresentado diferenças estatísticas entre si, os frangos alimentados com os níveis mais elevados de farelo de girassol nas rações apresentaram os piores resultados. Por outro lado as médias de consumo de ração não apresentaram este comportamento. Estes fatos explicam a piora nas conversões alimentares dos frangos alimentados com as rações que continham os níveis mais elevados de farelo de girassol.

Estes resultados sugerem que os tratamentos T4 ( $12 \%$ de farelo de girassol na ração entre 3 e 35 dias) e T7 ( $0 \%$ de farelo de girassol entre 0 e 21 dias e $12 \%$ entre 22 e 35 dias de idade) são adequados para o consumo de ração, mas não são para o ganho de peso dos frangos.

Ao que parece, os frangos consumiram ração para atender as suas exigências em energia, o que concorda com os achados de Pinheiro (1993), contudo há que se considerar que o farelo de girassol possui níveis elevados de fibra. Connel (1981) relata que altas concentrações de fibra na ração aumentam a taxa de passagem da digesta no trato gastrintestinal, com conseqüente redução no aproveitamento dos nutrientes. Em seus trabalhos, Zatari \& Sell (1990) também verificaram piora na conversão alimentar de frangos com 28 dias de idade alimentados com rações contendo 10 e $20 \%$ de farelo de girassol, suplementadas ou não com gordura, e atribuíram este fato à redução na metabolização da energia das mesmas, como conseqüência do aumento do teor de fibra proporcionado pelo farelo.

Bett (1999) demonstrou piora na metabolização da matéria seca e da energia bruta em rações de frangos de corte de 25 a 30 dias de idade, quando as mesmas continham inclusões acima de $15 \%$ de farelo de girassol, e também atribuíram este fato ao aumento dos teores de fibra decorrentes da adição do farelo na ração.

Tabela 3 - Efeito dos tratamentos e sexos sobre o ganho de peso (GP), consumo de ração (CR) e conversão alimentar (CA) dos frangos de corte entre 3 e 21 dias de idade

Table 3 - Effect of treatments and sexes on weight gain (WG), feed intake (FI) and feed:gain ratio (F:G) of broilers from 3 to 21 days of age

\begin{tabular}{|c|c|c|c|}
\hline \multirow{3}{*}{$\begin{array}{l}\text { Tratamentos } \\
\text { Treatments }\end{array}$} & \multicolumn{3}{|c|}{$\begin{array}{l}\text { Variáveis } \\
\text { Variables }\end{array}$} \\
\hline & GP $(\mathrm{g})$ & $\mathrm{CR}(\mathrm{g})$ & $\mathrm{CA}(\mathrm{g} / \mathrm{g})$ \\
\hline & $W G(g)$ & $F I(g)$ & $F: G(g / g)$ \\
\hline$\overline{1(0 \% \mathrm{I} 1, \mathrm{I} 2 \text { e I3) }}$ & 677,10 & 1017,29 & 1,50 \\
\hline $2(4 \% \mathrm{I} 1, \mathrm{I} 2$ e I3) & 693,33 & 1033,90 & 1,49 \\
\hline $3(8 \%$ I1, I2 e I3) & 674,36 & 986,97 & 1,46 \\
\hline $4(12 \% \mathrm{I} 1, \mathrm{I} 2$ e I3) & 682,10 & 1006,15 & 1,47 \\
\hline \multicolumn{4}{|l|}{ Sexo } \\
\hline \multicolumn{4}{|l|}{ Sex } \\
\hline Machos & $717,78^{a}$ & $1060,06^{\mathrm{a}}$ & 1,48 \\
\hline Males & & & \\
\hline $\begin{array}{l}\text { Fêmeas } \\
\text { Females }\end{array}$ & $645,66^{b}$ & $962,10^{\mathrm{b}}$ & 1,49 \\
\hline $\begin{array}{l}\text { Média } \\
\text { Mean }\end{array}$ & 681,72 & 1011,08 & 1,48 \\
\hline $\begin{array}{l}\text { F Tratamentos } \\
\text { F Treatments }\end{array}$ & NS & NS & NS \\
\hline $\begin{array}{l}\text { F Sexo } \\
F \text { Sex }\end{array}$ & $* *$ & $* *$ & NS \\
\hline $\begin{array}{l}\text { F Tratamentos x Sexo } \\
F \text { Treatments } x \text { Sex }\end{array}$ & NS & NS & NS \\
\hline $\begin{array}{l}\text { Coefic. de variação } \\
\text { Coefficient of variation }\end{array}$ & 5,71 & 5,31 & 2,10 \\
\hline
\end{tabular}


Tabela 4 - Efeito dos tratamentos e sexos sobre o ganho de peso (GP), consumo de ração (CR) e conversão alimentar (CA) dos frangos de corte entre 3 e 35 dias de idade

Table 4 - Effect of treatments and sexes on weight gain (WG), feed intake (FI) and feed:gain ratio (F:G) in broilers from 3 to 35 days of age

\begin{tabular}{|c|c|c|c|}
\hline \multirow{3}{*}{$\begin{array}{l}\text { Tratamentos } 1 \\
\text { Treatments }\end{array}$} & \multicolumn{3}{|c|}{$\begin{array}{l}\text { Variáveis } \\
\text { Variables }\end{array}$} \\
\hline & GP $(g)$ & $\mathrm{CR}(\mathrm{g})$ & $\mathrm{CA}(\mathrm{g} / \mathrm{g})$ \\
\hline & $W G(g)$ & $F I(g)$ & $F: G(g / g)$ \\
\hline $1(0 \%$ I1,I2 e I3) & 1750,50 & 2826,00 & $1,61^{\mathrm{c}}$ \\
\hline $2(4 \% \mathrm{I} 1, \mathrm{I} 2$ e I3) & 1713,88 & 2880,93 & $1,68^{\mathrm{ab}}$ \\
\hline $3(8 \%$ I1, I2 e I3) & 1674,42 & 2783,66 & $1,66^{\mathrm{b}}$ \\
\hline $4(12 \%$ I $1, \mathrm{I} 2$ e I3 $)$ & 1658,38 & 2800,75 & $1,69^{\mathrm{ab}}$ \\
\hline $5(0 \% \mathrm{I} 1,4 \% \mathrm{I} 2$ e I3) & 1715,68 & 2872,61 & $1,67^{\mathrm{ab}}$ \\
\hline $6(0 \% \mathrm{I} 1,8 \% \mathrm{I} 2$ e I3) & 1665,74 & 2788,43 & $1,68^{\mathrm{ab}}$ \\
\hline $7(0 \% \mathrm{I} 1,12 \% \mathrm{I} 2 \mathrm{e} \mathrm{I} 3)$ & 1635,03 & 2792,08 & $1,71^{\mathrm{a}}$ \\
\hline \multicolumn{4}{|l|}{$\operatorname{Sexo}^{2}$} \\
\hline \multicolumn{4}{|l|}{ Sex } \\
\hline Machos & $1796,15^{\mathrm{a}}$ & $2987,08^{a}$ & $1,66^{\mathrm{b}}$ \\
\hline Males & & & \\
\hline Fêmeas & $1579,18^{\mathrm{b}}$ & $2654,20^{\mathrm{b}}$ & $1,68^{\mathrm{a}}$ \\
\hline \multicolumn{4}{|l|}{ Females } \\
\hline Média & 1687,66 & 2820,64 & 1,67 \\
\hline \multicolumn{4}{|l|}{ Mean } \\
\hline F Tratamentos & NS & NS & $* *$ \\
\hline \multicolumn{4}{|l|}{$F$ Treatments } \\
\hline F Sexo & $* *$ & $* *$ & $*$ \\
\hline \multicolumn{4}{|l|}{$F \operatorname{Sex}$} \\
\hline F Tratamentos x sexo & NS & NS & NS \\
\hline$F$ Treatments $x$ sex & & & \\
\hline $\begin{array}{l}\text { Coefic. de variação } \\
\text { Coefficient of variation }\end{array}$ & 3,89 & 3,52 & 1,07 \\
\hline \multicolumn{4}{|c|}{$\begin{array}{l}{ }^{* *}(P<0.01){ }^{*}(P<0.05) \\
1 \text { a }>\text { b Médias seguidas por letras diferentes diferem entre si } \\
(P<0,05) \text { pelo teste de Tukey. } \\
2 \text { a } \quad \text { b Médias seguidas por letras diferentes diferem entre si } \\
(P<0,01) \text { pelo teste } F \text {. } \\
1 \text { a>b Means followed by different letters differ }(P<0.05) \text { by Tukey test. } \\
2 \text { a>b Means followed by different letters differ }(P<0.01) \text { by } F \text { test. }\end{array}$} \\
\hline
\end{tabular}

Neste experimento, os dados da Tabela 2 mostram aumento no teor de fibra das rações com os níveis crescentes de farelo de girassol. Isto pode explicar a piora nas médias de ganho de peso e conversão alimentar observadas quando os frangos consumiram as rações que continham os níveis mais elevados de farelo de girassol.

Para as variáveis ganho de peso, consumo de ração e conversão alimentar os frangos machos apresentaram melhores médias $(\mathrm{P}<0.01)$ que as fêmeas.

Desempenho dos frangos no periodo entre 3 e 42 dias de idade

Os dados de desempenho dos frangos de corte na fase de 3 a 42 dias de idade estão na Tabela 5.

R. Bras. Zootec., v.31, n.3, p.1418-1425, 2002 (suplemento)
Tabela 5 - Efeito dos tratamentos e sexos sobre o ganho de peso (GP), consumo de ração (CR) e conversão alimentar (CA) dos frangos de corte de 3 a 42 dias de idade

Table 5 - Effect of treatments and sexes on weight gain (WG), feed intake (FI) and feed:gain ratio (F:G) in broilers from 3 to 42 days of age

\begin{tabular}{|c|c|c|c|}
\hline \multirow{3}{*}{$\begin{array}{l}\text { Tratamentos } 1 \\
\text { Treatments }\end{array}$} & \multicolumn{3}{|c|}{$\begin{array}{l}\text { Variáveis } \\
\text { Variables }\end{array}$} \\
\hline & GP $(g)$ & $\mathrm{CR}(\mathrm{g})$ & $\mathrm{CA}(\mathrm{g} / \mathrm{g})$ \\
\hline & $W G(g)$ & $F I(g)$ & $F: G(g / g)$ \\
\hline $1(0 \%$ I1,I2 e I3) & 2250,19 & 4037,70 & 1,79 \\
\hline $2(4 \% \mathrm{I} 1, \mathrm{I} 2$ e I3) & 2224,58 & 4057,60 & 1,82 \\
\hline $3(8 \%$ I1, I2 e I3) & 2226,23 & 4004,05 & 1,80 \\
\hline $4(12 \% \mathrm{I} 1, \mathrm{I} 2 \mathrm{e} \mathrm{I} 3)$ & 2156,34 & 4004,17 & 1,86 \\
\hline $5(0 \%$ I $1,4 \%$ I 2 e I3) & 2194,85 & 4057,50 & 1,85 \\
\hline $6(0 \% \mathrm{I} 1,8 \%$ I 2 e I3) & 2190,42 & 3997,44 & 1,83 \\
\hline $7(0 \% \mathrm{I} 1,12 \% \mathrm{I} 2$ e I3 $)$ & 2227,81 & 4017,71 & 1,81 \\
\hline $8(0 \%$ I 1 e $\mathrm{I} 2$ e $4 \%$ I3 $)$ & 2186,57 & 3866,80 & 1,77 \\
\hline $9(0 \%$ I 1 e I 2 e $8 \%$ I3 $)$ & 2157,92 & 3835,42 & 1,78 \\
\hline $10(0 \%$ I 1 e I 2 e $12 \%$ I 3$)$ & 2209,66 & 3941,95 & 1,78 \\
\hline \multicolumn{4}{|c|}{ Sexo } \\
\hline \multicolumn{4}{|l|}{ Sex } \\
\hline Machos & $2330,60^{\mathrm{a}}$ & $4204,40^{\mathrm{a}}$ & 1,80 \\
\hline Males & & & \\
\hline Fêmeas & $2074,31^{b}$ & $3759,66^{\mathrm{b}}$ & 1,81 \\
\hline \multicolumn{4}{|l|}{ Females } \\
\hline \multicolumn{4}{|l|}{ Média } \\
\hline \multicolumn{4}{|l|}{ Mean } \\
\hline F Tratamentos & NS & NS & NS \\
\hline \multicolumn{4}{|l|}{$F$ Treatments } \\
\hline F Sexo & $* *$ & $* *$ & NS \\
\hline \multicolumn{4}{|l|}{$F \operatorname{Sex}$} \\
\hline F Tratamentos x sexo & NS & NS & NS \\
\hline$F$ Treatments $x$ sex & & & \\
\hline Coeficiente de variação & 7,10 & 7,54 & 2,84 \\
\hline Coefficient of variation & & & \\
\hline
\end{tabular}

Como se observa, os diferentes tratamentos experimentais não tiveram efeitos significativos $(\mathrm{P}>0.05)$ sobre as variáveis estudadas, demonstrando, portanto, que o farelo de girassol pode ser incluído em $12 \%$ nas rações dos frangos de corte, a partir do terceiro dia de idade.

Estes resultados contrastam com os obtidos por Silveira et al. (1967), que observaram redução linear no desempenho dos frangos de corte de 63 dias de idade alimentados com rações que continham 11,3\% de farelo de girassol, a partir dos 10 dias de idade, e atribuíram este fato a uma deficiência de lisina no farelo e ao seu alto teor de fibra.

Janssen \& Carré (1989) relataram que o complexo celulolítico das plantas, além de ser pouco digerido 
pelas aves, aumenta a perda endógena de proteína devido ao aumento da descamação intestinal, com conseqüente aumento na exigência dietética de aminoácidos, e também proporciona diminuição na concentração de energia nas rações.

Trabalhos como os de Costa (1974) e Zatari \& Sell (1990) enfatizaram a possibilidade de inclusão de níveis elevados de farelo de girassol (20\%) nas rações de frangos de corte, a partir do primeiro dia de idade, desde que sejam adequadamente suplementadas com lisina e energia.

El Sk et al. (1997), trabalhando com frangos de corte dos 18 aos 46 dias de idade, alimentados com rações contendo $20 \%$ de farelo de soja, verificaram a possibilidade de sua substituição completa pelo farelo de girassol, sem prejuízo aos seus desempenhos.

Bett (1999) demonstrou, conclusivamente, que ótimo desempenho dos frangos de corte pode ser obtido com rações, contendo até $15 \%$ de farelo de girassol, desde que sejam suplementadas com lisina e energia para atender as suas exigências nutricionais; e relata ainda que, uma vez obedecido este limite, o seu melhor nível de inclusão fica na dependência do seu custo no mercado.
O limite de $12 \%$ de farelo de girassol utilizado neste experimento pode ter impedido a obtenção de uma resposta mais conclusiva a respeito do seu nível máximo de inclusão nas rações dos frangos, contudo, deve-se ressaltar que o fator determinante para esta escolha foi a grande dificuldade da mistura das rações com níveis elevados do farelo, que necessitaram da adição de grande quantidade de óleo vegetal para atender a demanda energética dos frangos.

Para as variáveis ganho de peso e consumo de ração os machos apresentaram maiores médias $(\mathrm{P}<0.01)$, enquanto que para a conversão alimentar não houve diferenças $(\mathrm{P}>0.05)$ entre os sexos.

Desempenho econômico

$\mathrm{Na}$ Tabela 6 são apresentados os de índices de custos e de eficiência econômica, bem como o custo médio em ração por quilograma de frango vivo.

Os resultados mostram que o menor custo de produção de cada $\mathrm{kg}$ de peso vivo de frango, em ração, e o melhor índice de custo e de eficiência econômica foram obtidos quando os frangos foram submetidos ao tratamento $\mathrm{T} 8$, que consistiu em ração com $0 \%$ de farelo de girassol dos 3 aos 35 dias e com $4 \%$ de farelo de girassol dos 35 aos 42 dias de idade.

Tabela 6 - Custo médio em ração por kg de frango vivo, índice médio de custo e índice de eficiência econômica dos frangos (3-42 dias de idade)

Table 6 - Average ration cost per kilo of bird, mean cost index and economical efficiency index of broilers (from 3-42 days old)

\begin{tabular}{|c|c|c|c|}
\hline \multirow{3}{*}{$\begin{array}{l}\text { Tratamentos } \\
\text { Treatments }\end{array}$} & \multicolumn{3}{|c|}{$\begin{array}{l}\text { Variáveis } \\
\text { Variables }\end{array}$} \\
\hline & Custo em ração, $\mathrm{R} \$ / \mathrm{kg}$ PV & Índice de custo & Índice de eficiência econômica \\
\hline & Ration cost, $R \$ / \mathrm{kg} L W$ & Cost index & Economical efficiency index \\
\hline $1(0 \% \mathrm{I} 1, \mathrm{I} 2$ e I3) & 0,4823 & 100,90 & 99,10 \\
\hline $2(4 \%$ I1, I2 e I3) & 0,4941 & 103,36 & 96,64 \\
\hline $3(8 \%$ I1, I2 e I3) & 0,4886 & 102,21 & 97,79 \\
\hline $4(12 \%$ I1, I2 e I3) & 0,5087 & 106,42 & 93,58 \\
\hline $5(0 \% \mathrm{I} 1,4 \% \mathrm{I} 2$ e I3) & 0,4997 & 104,56 & 95,44 \\
\hline $6(0 \% \mathrm{I} 1,8 \% \mathrm{I} 2$ e I3) & 0,4949 & 103,53 & 96,47 \\
\hline $7(0 \%$ I1, $12 \%$ I2 e I3) & 0,4911 & 102,74 & 97,26 \\
\hline $8(0 \%$ I 1 e $\mathrm{I} 2$ e $4 \% \mathrm{I} 3)$ & 0,4780 & 100,00 & 100,00 \\
\hline $9(0 \%$ I1 e I 2 e $8 \%$ I3 $)$ & 0,4813 & 100,69 & 99,31 \\
\hline $10(0 \%$ I 1 e $\mathrm{I} 2$ e $12 \% \mathrm{I} 3)$ & 0,4823 & 100,90 & 99,10 \\
\hline
\end{tabular}




\section{Conclusões}

Pode-se incluir $12 \%$ de farelo de girassol nas rações de frangos de corte, sem prejuízo para o desempenho produtivo, sendo que o melhor desempenho econômico foi obtido quando os frangos foram alimentados com $0 \%$ de farelo de girassol dos 3 até 35 dias e $4 \%$ de farelo de girassol de 36 a 42 dias de idade.

\section{Literatura Citada}

BARBOSA, H.P.; FIALHO, E.T.; FERREIRA, A.S. et al. Triguilho para suínos nas fases inicial, de crescimento, crescimento e terminação. Revista da Sociedade Brasileira de Zootecnia, v.21, n.5, p.827-37, 1992.

BELLAVER, C.; FIALHO, E.T.; PROTAS, J.F.S et al. Radícula de malte na alimentação de suínos em crescimento e terminação. Pesquisa Agropecuária Brasileira, v.20, n.8, p.969974, 1985.

BETT, C.M. Utilização do farelo e da semente de girassol na alimentação de frangos de corte. Maringá: Universidade Estadual de Maringá, 1999. 39p. Dissertação (Mestrado em Zootecnia) - Universidade Estadual de Maringá, 1999.

CONNEL, A.M. Dietary fiber In: JOHNSON, L.R. (Ed.) Physiology of gastrointestinal tract. New York: Raven Press, 1981. p.1291-1299.

COSTA, C.P. Influência da lisina nas dietas contendo farelo de girassol para frangos de corte. Belo Horizonte: Universidade Federal de Minas Gerais, 1974. 35p. Dissertação (Mestrado em Zootecnia) - Universidade Federal de Minas Gerais, 1974.

DAGHIR, N.J.; RAZ, M.A.; UWAYJAN, M. Studies on the utilization of full fat sunflower seed in broiler ration. Poultry Science, v.59, n.10, p.2273-2278, 1980.

EL SK, GERENDAI, D.; GIPPERT, T. Complete substitution of sunflower meal for soybean meal with or without enzyme supplementation in broiler rations. Archiv Fur Geflugelkunde, v.61, n.1, p.8-14, 1997.

EMPRESA BRASILEIRA DE PESQUISA E AGROPECUÁRIA - EMBRAPA. Tabela de composição química e valores energéticos de alimentos para suínos e aves. 3.ed. Concórdia: Centro Nacional de Pesquisa de Suínos e Aves, 1991. 97p. (Documentos, 19).

IBRAHIM, M.A., EL ZUBEIR, E.A. Higher fiber sunflower meal in broiler chick diets. Animal Feed Science and Technology, v.33, n.3-4, p.343-347, 1991.

JANSSEM, W.M.M.A.; CARRÉ, B. Influence of fiber on digestibility of poultry feeds In: COLE, D.J.A.; HARESIGN, W. (Eds.) Recent developments in poultry nutrition. London: Butterworths, 1989. p.78-93.
MINARDI, I. Estudo sobre a composição bromatológica e coeficientes de digestibilidade do farelo de torta de girassol. Piracicaba: Escola Superior de Agricultura Luiz de Queiroz, 1969. 49p. Dissertação (Mestrado em Produção Animal) Escola Superior de Agricultura Luiz de Queiroz, 1969.

MUSHARAF, N.A. Effect of graded levels of sunflower meal in broiler diets. Animal Feed Science and Technology, v.33, n.1-2, p.129-137, 1991.

NATIONAL RESEARCH COUNCIL - NRC. Nutrient requirements of poultry. 9.ed., Washington, D.C.: 1994. 155p.

PINHEIRO, J.W. Soja integral processada pelo calor em rações de frangos de corte. Jaboticabal: Universidade Estadual Paulista, 1993. 175p. Tese (Doutorado em Zootecnia)Universidade Estadual Paulista, 1993.

RAD, F.H.; KESHAVARZ, K. Evaluation of the nutritional value of sunflower meal and the possibility of substitution of sunflower meal for soybean meal in poultry diets. Poultry Science, v.55, n.5, p.1757-1764, 1976.

ROSTAGNO, H.S.; ALBINO, L.F.T.; DONZELE, J.L. et al. Tabelas brasileiras para aves e suínos (Composição de alimentos e exigências nutricionais). Viçosa, MG: Unviersidade Federal de Viçosa. 2000. 141p.

SILVEIRA, J.; VELLOSO, L.; BECKER,M.N. et al. Farelo de girassol em substituição ao farelo de soja em rações de pintos. Boletim da Indústria Animal, v.24, n.8, p.129-138, 1967.

STRINGHINI, J.H.; CAFÉ, M.B.; FERNANDES, C.M. Avaliação do valor nutritivo do farelo de girassol para aves. In: REVISTA BRASILEIRA DE CIÊNCIA AVÍCOLA, Sup1.2, 2000, Campinas. Anais... Campinas: Fundação APINCO de ciência e tecnologia Avicolas, 2000. p.41.

UNIVERSIDADE FEDERAL DE VIÇOSA-UFV.1997. SAEGSistema de análises estatísticas e genéticas. Versão 7.1. Viçosa,MG. 150p. (Manual do usuário).

VALDIVIE, M.; SARDINAS, O.; GARCIA, J.A. The utilization of $20 \%$ sunflower seed meal in broiler diets. Cuban Journal of Agricultural Science, v.16, n.2, p.167-171, 1982.

ZATARI, I.M.; SELL, J.L. Sunflower meal as component of fatsuplemented diets for broiler chickens. Poultry Science, v.69, n.9, p.1503-1507, 1990.

WALDROUP, P.W.; HILlARD, C.M.; MITCHELL, R.J. Sunflower meal as a protein supplement for broiler diets. Feedstuffs, v.42, n.43, p.41, 1970.

Recebido em: 03/05/01 Aceito em: 18/03/02 